\title{
A study of pathological characteristics and BRAF V600E status in Langerhans cell histiocytosis of Vietnamese children
}

\author{
Thu Dang Anh Phan ${ }^{1}$, Bao Gia Phung ${ }^{2}$, Tu Thanh Duong ${ }^{1}$, Vu Anh Hoang ${ }^{3}$, \\ Dat Quoc Ngo ${ }^{1}$, Nguyen Dinh The Trinh ${ }^{4}$, Tung Thanh Tran ${ }^{4}$ \\ 'Department of Pathology, University of Medicine and Pharmacy at Ho Chi Minh City, Ho Chi Minh City; \\ 2Department of Pathology, City Children Hospital, Ho Chi Minh City; \\ ${ }^{3}$ Center for Molecular Biomedicine, University of Medicine and Pharmacy at Ho Chi Minh City, Ho Chi Minh City; \\ ${ }^{4}$ Department of Pathology, Children Hospital 1, Ho Chi Minh City, Vietnam
}

\begin{abstract}
Background: Langerhans cell histiocytosis (LCH) is more common in children than adults and involves many organs. In children, the BRAF V600E mutation is associated with recurrent and high-risk LCH. Methods: We collected paraffin blocks of 94 pediatric LCH patients to detect BRAF V600E mutation by sequencing. The relationship between BRAF V600E status and clinicopathological parameters were also critically analyzed. Results: BRAF V600E mutation exon 15 was detected in 45 cases (47.9\%). Multiple systems LCH showed a significantly higher BRAF V600E mutation rate than a single system $(p=.001)$. No statistical significance was evident for other clinical characteristics such as age, sex, location, risk organs involvement, and CD1a expression. Conclusions: In Vietnamese LCH children, the proportion of BRAF V600E mutational status was relatively high and related to multiple systems.
\end{abstract}

Key Words: Langerhans cell histiocytosis; BRAF V600E mutation; Sequencing

Received: July 27, 2020 Revised: November 22, 2020 Accepted: November 30, 2020

Corresponding Author: Thu Dang Anh Phan, MD, PhD, Department of Pathology, University of Medicine and Pharmacy at Ho Chi Minh City, Ho Chi Minh City 700000, Vietnam Tel: +84-838-558-411, Fax: +84-838-552-304, E-mail: phandanganhthu@ump.edu.vn

Langerhans cell histiocytosis (LCH) is a rare disease defined by proliferation of Langerhans cells with highly heterogeneous presentations and clinical courses [1,2]. The condition can occur at any age but is more common in children. $\mathrm{LCH}$ can involve one organ, so-called single system, or more than one organ, termed multisystem or multiple systems (MS-LCH). LCH has been referred to by various names, including localized eosinophilic granuloma of the bone, Letterer-Siwe disease, Hand-Schuller-Christian disease, and histiocytosis X [3,4]. Children under 2 years old with MS-LCH commonly exhibit risk organ involvement, such as the liver, spleen, and hematopoietic system. Although typical morphology can identify the pathologic Langerhans cells, confirming their nature requires positive staining for $\mathrm{CD} 1 \mathrm{a}$ and CD207 or identifying Birbeck particles under electron microscopy [5,6].

The clinical prognosis of LCH can be extremely variable. The patients with multiple systems, risk organ involvement likely have a more unsatisfactory outcome and are at risk for reactiva- tions [7]. Fortunately, recent molecular findings promise a targeted therapy for high-risk pediatric patients with risk organ involvement, for those who fail standard treatment and those with relapses [4].

$B R A F$ is an oncogene that has a critical role in the Ras-ERK signaling cascade, a primary regulator of cell growth, proliferation, differentiation, and apoptosis. Therefore, BRAF mutations contribute to many human cancers' pathogenesis, most commonly melanoma, thyroid papillary carcinoma, and colorectal carcinoma $[8,9]$. The primary mutation point is the valine codon in position 600 located in exon 15 (V600E mutation), which replaces nucleotide at $1799 \mathrm{~T} \rightarrow \mathrm{A}$ in the BRAF gene, resulting in the replacement of valine amino acid by glutamate [8-10].

The BRAF V600E mutation is also the potential target for treatment with Vemurafenib—an inhibitor used in many malignancies, most notably melanoma, and recently reported in LCH [9,11]. Thus, BRAF V600E may be a potential marker for targeted therapy in aggressive LCH. Several studies have shown 
that the presence of BRAF V600E mutation is associated with a higher risk of recurrence and organ involvement in pediatric LCH [12-14]. This study analyzed the BRAF V600E mutation by sequencing tumor DNA and the relationship between the genetic alteration and clinicopathological characteristics of LCH children.

\section{MATERIALS AND METHODS}

\section{Patients and sample collection}

The study consisted of 94 cases diagnosed with $\mathrm{LCH}$ at the Department of Pathology, Children's Hospital 1, Ho Chi Minh City, Vietnam, from 2012 to 2018. Formalin-fixed paraffin-embedded (FFPE) tissue with well-defined histology of LCH on hematoxylin and eosin $(\mathrm{H} \& \mathrm{E})$ stained sections and positive CD1a staining (using monoclonal antibody CD1a, clone 010, Dako, Glostrup, Denmark) were collected. We analyzed the intensity of CD1a expression as low expression (moderate membrane and cytoplasmic staining) and high expression (strong membrane and cytoplasmic staining).

All paraffin blocks were well preserved and available for DNA sequencing. All slides were re-examined to confirm the diagnosis and to select the paraffin blocks for molecular testing. Clinical information, age, sex, location, histopathology, and risk organ were obtained.

\section{Analysis of BRAF V600E mutation}

Tumor cells were selected based on H\&E slides and were targeted for DNA extraction by macrodissection scraping. DNA was isolated from a 5 - $\mu$ m-thick tumor using the ReliaPrep FFPE gDNA Miniprep System kit (Promega, Madison, WI, USA) according to the manufacturer's protocol. Amplification of the BRAF exon 15 was performed using TaKaRa Taq HotStart Polymerase (Takara Bio, Shiga, Japan) with primers BRAF600F (5'-ACTCTTCATAATGCTTGCTC-3') and BRAF-600R (5'-CCACAAAATGGATCCAGACA-3'). Polymerase chain reaction (PCR) included initial denaturation at $98^{\circ} \mathrm{C}$ for $3 \mathrm{~min}$ utes followed by 45 cycles of $98^{\circ} \mathrm{C}$ for 10 seconds, $60^{\circ} \mathrm{C}$ for 30 seconds, and $72^{\circ} \mathrm{C}$ for 40 seconds, with a final elongation of $72^{\circ} \mathrm{C}$ for 2 minutes. PCR product was purified enzymatically using the ExoSAP IT PCR Product Cleanup Reagent (Thermo Scientific, Waltham, MA, USA) to remove excess primers and dNTPs before Sanger sequencing using the BigDye Terminator v3.1 Kit and the ABI 3500 Genetic Analyzer (Applied Biosystems, Foster City, CA, USA). PCR fragment was sequenced and analyzed in both directions. The sequence was finally compared to the reference sequence of the BRAF gene (GenBank accession number: NG_007873).

\section{Statistical analyses}

The correlation between BRAF V600E mutation and age, sex, tumor location, and organ involvement was analyzed by the chisquare test. $\mathrm{p}<.05$ was considered a significant difference. Statistical analyses were performed using SPSS ver. 16.0 (SPSS Inc., Chicago, IL, USA).

\section{RESULTS}

\section{Characteristics of pediatric $\mathrm{LCH}$}

In 94 cases of $\mathrm{LCH}$, the median age was 3.02 years (range, 0 to 12 years; minimum, 10 days old). $\mathrm{LCH}$ was most frequently found in the age group of under $3(60.6 \%)$, in which 1-year-old patients were predominant $(56.1 \%, 32 / 57$ cases). $\mathrm{LCH}$ was more common in males than in females, with a male: female ratio of 1.4. Soft tissues were the most common biopsy location $(n=39$, $41.5 \%)$, followed by the skin ( $\mathrm{n}=30,31.9 \%)$, bones ( $\mathrm{n}=18$, $19.1 \%)$, lymph nodes $(n=6,6.4 \%)$ and lung $(n=1,1.1 \%)$. The clinicopathologic features are summarized in Table 1. Fortyeight patients $(51.1 \%)$ had single system involved, while 46 patients (48.9\%) had multiple systems involved. Risk organ involvement was observed in 35 patients (37.2\%). The Langerhans cells were pathologically characterized by abundant pale cyto-

Table 1. The clinical characteristics and BRAF V600E status of Vietnamese pediatric Langerhans cell histiocytosis

\begin{tabular}{|c|c|c|}
\hline Clinical parameter & Total & $\begin{array}{l}\text { BRAF V } 600 \mathrm{E} \\
\text { mutated }\end{array}$ \\
\hline No. & 94 & $45(47.9)$ \\
\hline Age (yr) & $\begin{array}{c}3.0 \pm 2.9 \\
(0-12 \mathrm{yr} ; \text { minimum, } 10 \text { days })\end{array}$ & \\
\hline Under 3 yr & $57(60.6)$ & $27(46.6)$ \\
\hline $\begin{array}{l}\text { Sex } \\
\text { Male } \\
\text { Female }\end{array}$ & $\begin{array}{l}55(58.5) \\
39(41.5)\end{array}$ & $\begin{array}{l}25(55.6) \\
20(44.4)\end{array}$ \\
\hline $\begin{array}{l}\text { Location } \\
\text { Skin } \\
\text { Lymph node } \\
\text { Soft tissues } \\
\text { Bone } \\
\text { Lung }\end{array}$ & $\begin{array}{c}30(31.9) \\
6(6.4) \\
39(41.5) \\
18(19.1) \\
1(1.1)\end{array}$ & $\begin{array}{c}13(28.9) \\
2(4.4) \\
23(51.1) \\
7(15.5) \\
0\end{array}$ \\
\hline $\begin{array}{l}\text { System involvement } \\
\text { Single system } \\
\text { Multiple system }\end{array}$ & $\begin{array}{l}48(51.1) \\
46(48.9)\end{array}$ & $\begin{array}{l}15(31.3) \\
30(65.2)\end{array}$ \\
\hline $\begin{array}{l}\text { Risk organ involvement } \\
\text { CD1a expression }\end{array}$ & $35(37.2)$ & $18(51.4)$ \\
\hline $\begin{array}{l}\text { Low } \\
\text { High }\end{array}$ & $\begin{array}{l}31(33.0) \\
63(67.0)\end{array}$ & $\begin{array}{l}12(38.7) \\
33(52.4)\end{array}$ \\
\hline
\end{tabular}

Values are presented as number (\%). 
plasm and folded nuclei (Fig. 1) that expressed CDla. The intensity of CD1a staining was also divided into low and high expression (33\% vs. $67 \%$ ).

\section{$B R A F$ mutation analysis}

Sequencing analyses for all 94 patients successfully defined BRAF V600E status. BRAF V600E mutation exon 15 was found in 45 cases (47.9\%) (Fig. 2). In Table 2, we demonstrate the relation between $B R A F \mathrm{~V} 600 \mathrm{E}$ mutation and clinical parameters. Multiple system LCH showed a significantly higher BRAF V600E mutation rate than the single system LCH $(\mathrm{p}=.001)$. There was no significant difference between $B R A F$ status and other clinical characteristics such as age, sex, location, risk organs involvement, and $\mathrm{CD} 1 \mathrm{a}$ expression.
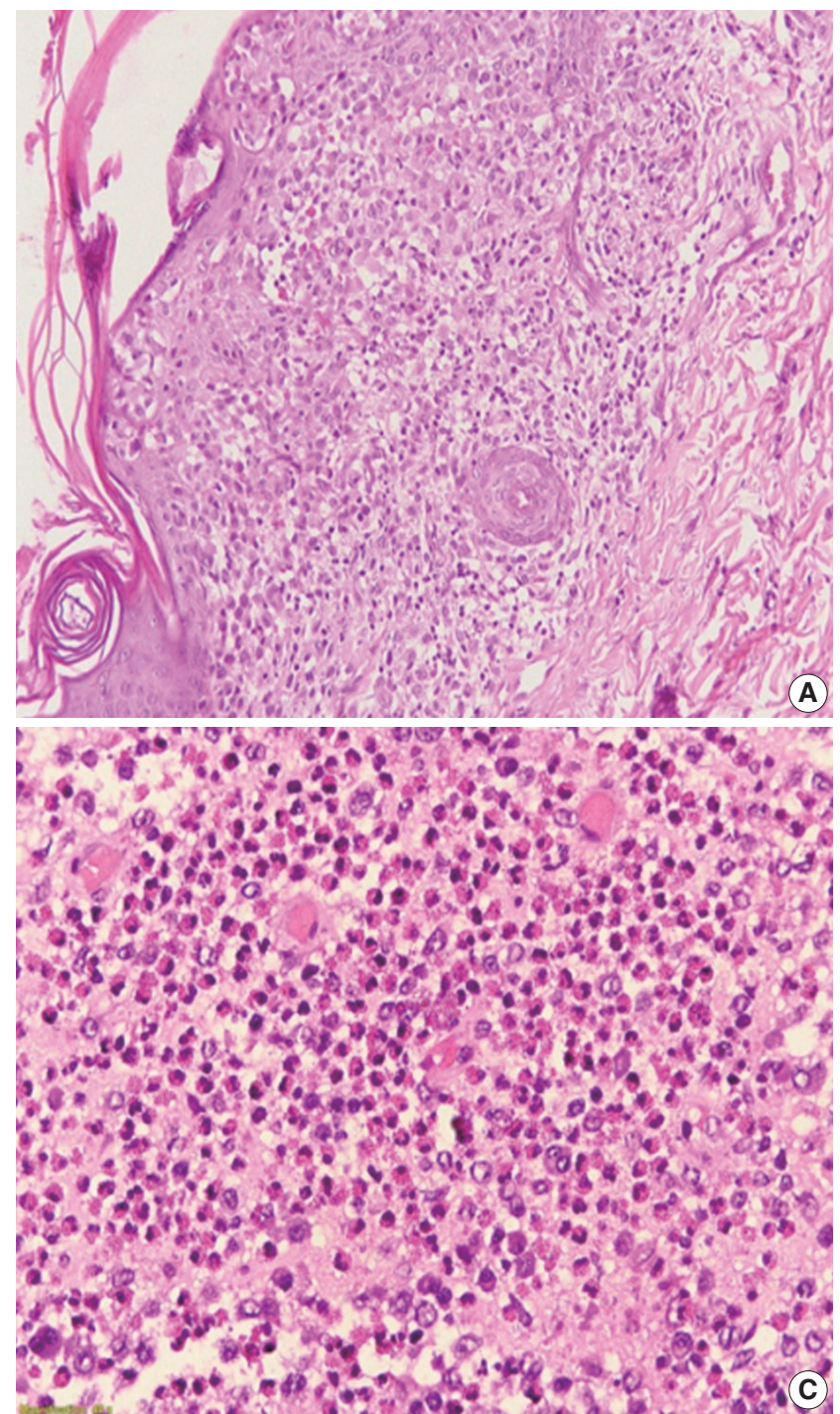

\section{DISCUSSION}

BRAF mutations play the leading role in the oncogenesis of human cancers because of their involvement in the Ras-ERK signaling cascade, which regulates cellular motility, proliferation, and survival. Recent studies have found somatic mutations that trigger mitogen-activated protein kinase signaling in most LCH patients [13,15-19]. In particular, the BRAF V600E mutation is found in more than $50 \%$ of $\mathrm{LCH}$ lesions in children, while other modifications of the codon V600 such as V600K, V600D, or $\mathrm{V} 600 \mathrm{R}$ are not present in this disease [20]. The BRAF mutation presentation appears to be complicated; however, the most common point mutation is $\mathrm{V} 600 \mathrm{E}$ (the valine codon in position 600 , located in exon 15). Most BRAF mutations are detected in

Fig. 1. Langerhans cell histiocytosis on hematoxylin and eosin staining: (A) skin lesion, (B) soft tissue of the head and neck, (C) bone lesion, and (D) lymph node lesion. 


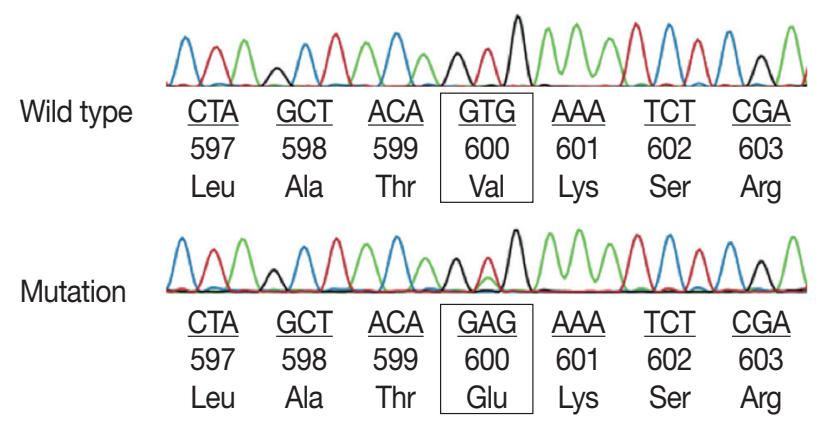

Fig. 2. The BRAF V600E status in pediatric Langerhans cell histiocytosis.

Table 2. The correlation of BRAF V600E status and clinical parameters of Vietnamese $\mathrm{LCH}$ patients $(n=94)$

\begin{tabular}{|c|c|c|c|}
\hline Clinical parameter & $\begin{array}{c}\text { BRAF V600E } \\
\text { mutated }\end{array}$ & $\begin{array}{l}\text { BRAF V600E } \\
\text { Wild type }\end{array}$ & $\mathrm{p}$-value \\
\hline Age (yr) & & & .903 \\
\hline$<3$ & 27 & 30 & \\
\hline$\geq 3$ & 18 & 19 & \\
\hline Sex & & & .577 \\
\hline Male & 25 & 30 & \\
\hline Female & 20 & 19 & \\
\hline Skin lesions & & & .546 \\
\hline Present & 13 & 17 & \\
\hline Absent & 32 & 32 & \\
\hline Soft tissue & & & .070 \\
\hline Present & 23 & 16 & \\
\hline Absent & 22 & 33 & \\
\hline Bone lesions & & & .396 \\
\hline Present & 7 & 11 & \\
\hline Absent & 38 & 38 & \\
\hline System involvement & & & .001 \\
\hline Single system & 15 & 33 & \\
\hline Multiple systems & 30 & 16 & \\
\hline Risk organ involvement & 18 & 17 & .595 \\
\hline CD1a expression & & & .212 \\
\hline Low & 12 & 19 & \\
\hline High & 33 & 30 & \\
\hline
\end{tabular}

LCH, Langerhans histiocytosis; NS, nonsignificant.

exons 11 and 15 by DNA-based sequencing assays [8]. In particular, more than $80 \%$ of all BRAF mutations are in exon 15 , which results in changing valine for glutamic acid at codon 600 (V600E) [10]. Exon 11 mutations seem to be rare in LCH. Alayed et al. [21] detected BRAF mutations in LCH by pyrosequencing assays and found exon 15 BRAF V600E mutation and no exon 11 mutations in all cases.

This study found $47.9 \%$ of cases with $B R A F$ mutations detected in exon 15 (BRAF V600E). Our data showed that the BRAF V600E mutation in Vietnamese pediatric LCH was relatively high but unrelated to sex, age, and risk organ involvement. In previous studies on Caucasian children, BRAF mutation frequency varied from $33 \%$ to $69 \%[12,13,16,19,22]$. The study of Heritier et al. [12] on 315 pediatric LCH patients determined
173 cases (54.6\%) with BRAF V600E mutation. They also showed a significant relationship between BRAF V600E mutation with age under 3 years old and multisystem disease, mostly when there was a risk of organ involvement. Badalian-Very et al. [23] also reported that the incidence of BRAF V600E mutation was $57 \%$ in $61 \mathrm{LCH}$ patients, predominantly in patients with bone involvement. The mutation rate was also reportedly higher in young patients, especially children under age 15 . Ozer et al. [24] showed that $70 \%$ of pediatric $\mathrm{LCH}$ patients younger than 2 years of age significantly harbored BRAF V600E mutation. However, the ratio of $B R A F \mathrm{~V} 600 \mathrm{E}$ status in pediatric $\mathrm{LCH}$ reported in some Asian populations was lower. Sasaki et al. [25] demonstrated 21\% BRAF V600E mutations in Japanese patients (4/19 cases); Go et al. [26] showed 25\% (7/28 cases) in South Korean patients. These studies showed a different BRAF V600E status across the various population, which raised a possible question of racial involvement on genetic profile.

Moreover, the BRAF V600E mutation status showed variable distribution in some specific organs. Liu et al. [27] showed that $50 \%$ of bone lesions in the head and neck (18/36 cases) were identified with BRAF V600E mutation. Other studies found the transformation in over $70 \%$ of skin cases $[12,24]$, especially in multifocal skin involvement and multisystem disease. In the present study, the BRAF V600E mutation was detected mostly in $\mathrm{LCH}$ of the soft tissues (51.1\%), followed by skin (28.9\%), bone (15.5\%), and lymph nodes (4.4\%). In our study, 13/30 (43.3\%) skin cases harbored BRAF V600E mutation, lower than Ozer et al. [24] (77.8\%) and Heritier et al. [12] (77.0\%). False-negative results may occur in small-sized tumors such as skin lesions due to an insufficient amount of tumor cells. In this study, 7/18 (38.9\%) cases of LCH bone lesions harbored BRAF mutation; therefore, the current decalcifying solution possibly did little harm to DNA quality. Furthermore, no significant relation between BRAF V600E status and LCH location was observed in this study and others [12,24].

In 94 patients of this study, BRAF V600E mutation was significantly associated with multisystem involvement $(\mathrm{p}=0.001)$. Similarly, Heritier et al. [12] showed that BRAF V600E mutation correlated with high-risk LCH, including multiple systems and risk organ involvement, resulting in permanent, irreversible damage. Adding to these points, Heritier et al. [12] showed that patients with BRAF V600E more commonly displayed resistance to combined vinblastine corticosteroid therapy, higher reactivation rate, long-term consequences from disease or treatment. Ozer et al. [24] also found a statistical relationship between BRAF mutation and risk organ lesions. However, in this study, risk or- 
gan lesions showed no significant relation to $B R A F$ status. The prevalence of LCH BRAF mutation and its association with increased risk condition such as multiple systems or risk organs involvement possibly suggests a targeted treatment using $B R A F$ inhibitors for those that harbor the mutation.

In conclusion, the BRAF V600E status was detected with high frequency in Vietnamese pediatric LCH and may become a useful prognostic marker due to its association with multiple system $\mathrm{LCH}$. The identification of aggressive $\mathrm{LCH}$ based on genetic alterations is required for disease management and $B R A F$ inhibitors.

\section{Ethics Statement}

The study was approved by the Institutional Review Board of Biomedical Research at the Children's Hospital (IRB No. 1693/Children's Hospital 1; date: July 22, 2019) and performed in accordance with the principles of the Declaration of Helsinki. Written informed consents were obtained.

\section{ORCID}

Thu Dang Anh Phan Bao Gia Phung Vu Anh Hoang Dat Quoc Ngo Nguyen Dinh The Trinh Tung Thanh Tran Tu Thanh Duong

https://orcid.org/0000-0002-4062-0904
https://orcid.org/0000-0002-0875-1285
https://orcid.org/0000-0002-6564-6799
https://orcid.org/0000-0003-4232-6001
https://orcid.org/0000-0003-1461-0216
https://orcid.org/0000-0001-6236-3892
https://orcid.org/0000-0001-5511-7175

\section{Author Contributions}

Conceptualization: TDAP, BGP, TTD, VAH, DQN, NDTT, TTT. Data curation: TDAP, BGP, TTD. Formal analysis: TDAP, BGP, TTD. Funding ac-quisition: TDAP, BGP, TTD. Methodology: TDAP, BGP, TTD, VAH. Re-sources: NDTT, TTT, TDAP, BGP. Supervision: DQN, NDTT, TTT. Writing-original draft: TDAP, BGP, TTD. Writing_review \& editing: TDAP, QDN. Approval of final manuscript: all authors.

\section{Conflicts of Interest}

The authors declare that they have no potential conflicts of interest.

\section{Funding Statement}

This work was funded partly by the University of Medicine and Pharmacy at Ho Chi Minh city.

\section{Acknowledgments}

We thank Professor Lewis Hassell, Department of Pathology, Oklahoma University Health Sciences Center, for English proofreading.

\section{References}

1. Guyot-Goubin A, Donadieu J, Barkaoui M, Bellec S, Thomas C, Clavel J. Descriptive epidemiology of childhood Langerhans cell histiocytosis in France, 2000-2004. Pediatr Blood Cancer 2008; 51: 71-5.

2. Salotti JA, Nanduri V, Pearce MS, Parker L, Lynn R, Windebank KP. Incidence and clinical features of Langerhans cell histiocytosis in the UK and Ireland. Arch Dis Child 2009; 94: 376-80.

3. Arceci RJ. The histiocytoses: the fall of the Tower of Babel. Eur J Cancer 1999; 35: 747-67.

4. Gadner H, Minkov M, Grois N, et al. Therapy prolongation im- proved outcome in multisystem Langerhans cell histiocytosis. Blood 2013; 121: 5006-14.

5. Abla O, Weitzman S. Treatment of Langerhans cell histiocytosis: role of BRAF/MAPK inhibition. Hematology Am Soc Hematol Educ Program 2015; 2015: 565-70.

6. Birbeck MS, Breathnach AS, Everall JD. An electron microscope study of basal melanocytes and high-level clear cells (Langerhans cell) in vitiligo. J Investig Dermatol 1961; 37: 51-64

7. Minkov M. Multisystem Langerhans cell histiocytosis in children: current treatment and future directions. Paediatr Drugs 2011; 13: 75-86.

8. Davies H, Bignell GR, Cox C, et al. Mutations of the BRAF gene in human cancer. Nature 2002; 417: 949-54.

9. Fiskus W, Mitsiades N. B-Raf inhibition in the clinic: present and future. Annu Rev Med 2016; 67: 29-43.

10. Wooster R, Futreal AP, Stratton MR. Sequencing analysis of $B R A F$ mutations in human cancers. Methods Enzymol 2006; 407: 218-24.

11. Ascierto PA, Kirkwood JM, Grob JJ, et al. The role of BRAF V600 mutation in melanoma. J Transl Med 2012; 10: 85.

12. Heritier S, Emile JF, Barkaoui MA, et al. BRAF mutation correlates with high-risk Langerhans cell histiocytosis and increased resistance to first-line therapy. J Clin Oncol 2016; 34: 3023-30.

13. Berres ML, Lim KP, Peters T, et al. BRAF-V600E expression in precursor versus differentiated dendritic cells defines clinically distinct LCH risk groups. J Exp Med 2015; 212: 281.

14. Mehes G, Irsai G, Bedekovics J, et al. Activating BRAF V600E mutation in aggressive pediatric Langerhans cell histiocytosis: demonstration by allele-specific PCR/direct sequencing and immunohistochemistry. Am J Surg Pathol 2014; 38: 1644-8.

15. Brown NA, Furtado LV, Betz BL, et al. High prevalence of somatic MAP2K1 mutations in BRAF V600E-negative Langerhans cell histiocytosis. Blood 2014; 124: 1655-8.

16. Haroche J, Charlotte F, Arnaud L, et al. High prevalence of $B R A F$ V600E mutations in Erdheim-Chester disease but not in other non-Langerhans cell histiocytoses. Blood 2012; 120: 2700-3.

17. Nelson DS, Quispel W, Badalian-Very G, et al. Somatic activating ARAF mutations in Langerhans cell histiocytosis. Blood 2014; 123: 3152-5.

18. Sahm F, Capper D, Preusser M, et al. BRAFV600E mutant protein is expressed in cells of variable maturation in Langerhans cell histiocytosis. Blood 2012; 120: e28-34.

19. Satoh T, Smith A, Sarde A, et al. B-RAF mutant alleles associated with Langerhans cell histiocytosis, a granulomatous pediatric disease. PLoS One 2012; 7: e33891.

20. Ballester LY, Cantu MD, Lim KP, et al. The use of BRAF V600E mutation-specific immunohistochemistry in pediatric Langerhans cell histiocytosis. Hematol Oncol 2018; 36: 307-15.

21. Alayed K, Medeiros LJ, Patel KP, et al. BRAF and MAP2K1 mutations in Langerhans cell histiocytosis: a study of 50 cases. Hum Pathol 2016; 52: 61-7.

22. Roden AC, Hu X, Kip S, et al. BRAF V600E expression in Langerhans cell histiocytosis: clinical and immunohistochemical study on 25 pulmonary and 54 extrapulmonary cases. Am J Surg Pathol 2014; 38: 548-51.

23. Badalian-Very G, Vergilio JA, Degar BA, et al. Recurrent BRAF mutations in Langerhans cell histiocytosis. Blood 2010; 116: 191923.

24. Ozer E, Sevinc A, Ince D, Yuzuguldu R, Olgun N. BRAF V600E 
mutation: a significant biomarker for prediction of disease relapse in pediatric Langerhans cell histiocytosis. Pediatr Dev Pathol 2019; 22: 449-55.

25. Sasaki Y, Guo Y, Arakawa F, et al. Analysis of the BRAFV600E mutation in 19 cases of Langerhans cell histiocytosis in Japan. Hematol Oncol 2017; 35: 329-34.
26. Go H, Jeon YK, Huh J, et al. Frequent detection of $B R A F(\mathrm{~V} 600 \mathrm{E})$ mutations in histiocytic and dendritic cell neoplasms. Histopathology 2014; 65: 261-72.

27. Liu X, Zhang Y, Zhou CX. High prevalence of BRAF V600E mutations in Langerhans cell histiocytosis of head and neck in Chinese patients. Int J Surg Pathol 2019; 27: 836-43. 